\title{
MEMÓRIA E (NÃO) IDENTIDADE NO SUVENIR CARIOCA: ALGUNS RECORTES HISTÓRICOS
}

\author{
Isabella Vicente Perrotta*
}

Resumo

Tomando como objeto de estudo os artefatos que têm como função representar e lembrar o Rio de Janeiro para seus visitantes, este artigo pretende mostrar como o suvenir turístico - de uma maneira geral, e desde o século 19 - se apropria das mesmas construções imputadas aos destinos turísticos, inicialmente na literatura, postais, guias, matérias jornalísticas, gravuras, e fotografias; depois no cinema e na TV e, mais recentemente, nas redes sociais, blogs de conteúdo e sites de busca. Para o turista, reconhecer presencialmente o que já é pré-conhecido faz parte de uma necessidade de confirmação daquilo que lhe foi anunciado, mesmo que isso soe déjà-vu. Assim, tanto 0 cartão postal (de outrora), quanto o suvenir (ainda hoje), que deveriam ser símbolo do singular e do local, acabam sendo também a confirmação daquilo que já se conhecia antes da viagem. Acabam subvertendo-se ao impessoal, global, disseminado. Considerando que o Rio de Janeiro, historicamente, foi o principal acesso ao Brasil e, ainda hoje, é a cidade mais visitada do país, pretende-se mostrar como alguns suvenires ocupam, lugar miscigenógico e/ou sinestésico de Brasil, exaltando a diversidade de uma natureza que não está exatamente presente na cidade, mas se confunde com a "selva" (natural e cultural) a que o Rio era (e ainda é) associado. No artigo, os suvenires do Rio de Janeiro serão citados em recortes históricos exemplares. A análise empírica dos mesmos, dialoga com conceitos de memória e patrimônio.

Palavras Chave: Suvenir turístico. Rio de Janeiro. História do Turismo.

\section{MEMORY AND (NOT) IDENTITY IN THE CARIOCA SOUVENIR: SOME HISTORICAL CUTS}

This article intends to show how the tourist souvenirs of Rio de Janeiro, since the 19th century, appropriates the same constructions imputed to the tourist destinations, initially by literature, postcards, guides, newspaper articles, engravings, and photographs, them by movies, and more recently from social networks, content blogs and search engines. The traveler needs to recognize in person what was previously presented to him, to confirm what was announced or promised as an experience. Although this sounds déjà-vu. In this process, the souvenir, which should function as anchors for the memory of something singular and local, also ends up subverting itself to the impersonal, since they are representations of what is previously known and very widespread. Considering that Rio de Janeiro was historically, and still today is, the main access to Brazil, and is the most visited city of the country, this article intended to show how some souvenirs portray a certain miscegenation and / or synesthesia of Brazil, extolling the diversity of a nature that is not exactly present in Rio, but is confused with wild images to which the city is associated. The souvenirs of Rio de Janeiro will be treated in exemplary historical cuts, under the light of concepts such as memory and imaginary. The empirical analysis of the same, dialogues with concepts of memory and patrimony.

Keywords: Tourist souvenirs. Rio de Janeiro. History of Tourism.

\section{MEMORIA Y (NO) IDENTIDAD EN EL SUVENIR CARIOCA: ALGUNOS RECORTES HISTÓRICOS}

Tomando como objeto de estudio los artefactos que tienen como función representar y recordar a Río de Janeiro para sus visitantes, este artículo pretende mostrar cómo el suvenir turístico -de una manera general, y desde el siglo 19- se apropia de las mismas construcciones imputadas a los destinos turísticos, inicialmente en la literatura, postales, guías, materias periodísticas, grabados, y fotografías; después en el cine y la televisión y, más recientemente, en las redes sociales, blogs de contenido y sitios de búsqueda. Para el turista, reconocer presencialmente lo que ya es pre-conocido forma parte de una necesidad de confirmación de lo que le fue anunciado, aunque eso suene déjà-vu. Así, tanto la postal (de otrora), como el suvenir (aún hoy), que deberían ser símbolo del singular y del local, acaban siendo también la confirmación de lo que ya se conocía antes del viaje. Se acaban subvirtiéndose a lo impersonal, global, diseminado. En el caso de Río de Janeiro, históricamente, fue el principal acceso a Brasil y, aún hoy, es la ciudad más visitada del país, se pretende mostrar cómo algunos suvenires ocupan, lugar miscigenógico y / o sinestésico de Brasil, exaltando la diversidad de una naturaleza que no está exactamente presente en la ciudad, pero se confunde con la "selva" (natural y cultural) a la que el Río era (y aún es) asociado. En el artículo, los suvenires de Río de Janeiro serán citados en recortes históricos ejemplares. El análisis empírico de los mismos, dialoga con conceptos de memoria y patrimonio.

Palabras clave: Suvenir turístico. Rio de Janeiro. História del Turismo.

* Doutora em História, FGV-Rio. Mestre em Design, Puc-Rio. Coordenadora adjunta do Mestrado Profissional em Economia Criativa da ESPM-Rio. Hybris Design | ESPM Rio. www.hybris.com.br [isabella@hybris.com.br ]

Licenciada por Creative Commons Atribuição Não Comercial / Sem Derivações/ 4.0 / Internacional 


\section{INTRODUÇÃO}

Esse artigo, de caráter essencialmente teórico e analítico-descritivo, trata de produtos realizados em série, que podem ser considerados os primeiros suvenires da cidade do Rio de Janeiro. Serão abordados tanto produtos impressos (como estampas, gravuras e álbuns), quanto manufaturas utilitárias e decorativas.

Importa dizer que esses produtos, antes de servirem de lembrança para turistas, funcionaram como recordação de viajantes. Considera-se viajante um termo mais abrangente do que turista, e anterior a ele. No século XIX - ponto de partida dessa reflexão -, o turismo já começava a se desenhar na Europa (os primeiros guias, os primeiros grandes hotéis, as malas de grife, o surgimento do vocábulo tour etc), mas os viajantes eram as pessoas que exploravam e mapeavam 0 mundo (por necessidade de sobrevivência, pelo ímpeto da conquista, pela curiosidade científica etc), superando precários meios de transporte para grandes distâncias e passando por lugares que ainda não dispunham de condições razoáveis de acomodação e restauração.

Os viajantes vivenciavam enfrentamentos culturais e de idioma, mas voltavam para suas terras com muito a contar sobre lugares desconhecidos. Foram os responsáveis pela criação de imagens e imaginários de lugares que se tornariam destinos turísticos. Alguns dos suvenires que serão abordados aqui serviram justamente para que esses viajantes pudessem contar um pouco dessas histórias, e preservar suas memórias, em suas terras de origem.

Lembranças de lugares podem ser mentais, mas essas tendem a se dissipar e não podem ser ofertadas. É a materialidade que funciona como âncora de memória. Lembranças de lugares podem ter uma materialidade genuinamente natural, como um punhado de terra ou uma concha do mar, mas para além do fato de que essas nem sempre são preserváveis -, é a transformação da matéria que a confere significado.

A interação do homem com a sua materialidade envolve processos sociais, culturais, tecnológicos e econômicos (DOHMANN, 2017). Assim, hábitos culturais passaram a ser registrados graficamente, animais passaram a ser empalhados, comidas passaram a ser processadas, objetos passaram a ser estampados com paisagens e o suvenir passou a ser uma grande indústria, nem sempre tão representativa da identidade local quanto o visitante quer acreditar que seja. Ou mesmo gostaria que fosse. Hoje, empresas globais fornecem suvenires locais para várias cidades do planeta. Às vezes com uma mesma estampa (por exemplo: sol, praia, surfe) e diferentes assinaturas (como: Havaí, Costa Rica, Rio de Janeiro).

Mais do que ser uma âncora de memória de um local visitado, ou de uma experiência vivenciada, o suvenir funciona também para construir a memória de algo que não se viu ou não se vivenciou. Pode-se visitar o Rio de Janeiro e não ir à Copacabana, mas levar consigo um suvenir com a representação do calçadão de Copacabana. Esse objeto tornará quase crivel a memória de se ter conhecido a praia mais famosa da cidade, uma vez que foi adquirido na própria cidade.

O suvenir se apropria das mesmas construções imputadas aos destinos turísticos e reproduz os mesmos estereótipos que os turistas conheceram antes de viajar. E, para o turista, reconhecer o que estava no seu imaginário faz parte de uma necessidade de confirmação daquilo que the foi anunciado. Por isso, "não é a imagem que produz o imaginário, mas o contrário. A existência de um imaginário determina a existência de um conjunto de imagens" (MAFFESOLI, 2001, p.76). Nesse sentido, o imaginário é uma realidade, e as imagens tentam reproduzir, transmitir ou reforçar essa realidade. 0 suvenir que circula fora do seu local de origem (que, de fato é a intenção de tal artefato) também ajuda a construir esse imaginário. São imagens e imaginário se replicando, se alimentando e se reconstruindo continuamente.

Esse trabalho inicia apresentando conjuntos de produtos impressos (estampas), produzidos em série no Brasil e no exterior, desde a primeira metade do século XIX, reproduzindo paisagens, cenas e personagens da cidade do Rio de Janeiro. Volta-se depois para as peças manufaturadas seriadas em porcelana, cerâmica e vidro, sempre de produção estrangeira, que serviram de suporte para a paisagem carioca nas primeiras décadas do século XX. Ao final, tratamos de manufaturas brasileiras, surgidas nas décadas de 1930 e 1950, de caráter mais artesanal (ainda assim, produzidas em quantidades volumosas), onde a representação da cidade era mais sintética.

Cabe observar que a intenção do artigo foi a de apresentar aqueles que seriam os primeiros suvenires do Rio, entre os séculos XIX e XX, mas - a título de contextualização, um breve panorama dos atuais suvenires da cidade será fornecido ao final.

\section{FONTES, REFERÊNCIAS E METODOLOGIA}

Essa é uma pesquisa empírica, de longa vivência, sobre a representação da cidade do Rio de Janeiro, que vem sendo desdobrada em recortes diversos há muitos anos. Iniciou-se ainda na década 
de 1990 quando colecionávamos impressos com marcas (símbolos ou logotipos de produtos ou serviços) que estampavam ícones da cidade.

A questão do suvenir apareceu na pesquisa de doutoramento - que versava sobre a construção do Rio como destino turístico - quando nos perguntamos como seria a imagem da cidade, no exterior, no século XIX. Buscávamos quais representações circulavam, onde e como circulavam. Fossem narrativas literárias ou jornalísticas, escritas ou ilustradas, descritivas ou simbólicas.

Partimos do pressuposto que foi o grande contingente de viajantes que passaram pelo Rio de Janeiro, especialmente aqueles conhecidos como "artistas viajantes", o responsável pela construção da ideia de que a cidade era desejável. À tal premissa acrescentamos a hipótese de que a construção de um imaginário exótico e paradisíaco do Rio não foi inevitável, mas uma opção consciente.

A observação analítica, então, vem se dando a partir de fontes documentais primárias, em acervos públicos, privados e comerciais (antiquários), além de suas exibições em exposições e reproduções em livros, revistas, artigos e sites. Complementa a pesquisa empírica 0 acesso a fontes diretas (pesquisadores e colecionadores).

Sobre as estampas do século XIX, ainda que sejam consideradas "obras raras", há exemplares daquelas citadas nesse artigo depositados em vários arquivos da cidade do Rio de Janeiro, além de em outras brasilianas fora da cidade e do país, posto que foram produzidas em série.

Outro detalhe é que as gravuras eram impressas a traço preto, e colorizadas (ou não) à mão por diferentes artistas. Daí muitos exemplares serem diferentes nos distintos acervos em que se encontram. Acervos representativos são a Seção de Iconografia da Biblioteca Nacional, o Museu da Chácara do Céu, a Coleção Paulo Geyer, o Instituto Moreira Sales, o Instituto Histórico Geográfico Brasileiro e a Brasiliana Itaú, entre outros. Não é incomum a reprodução de parte significativa dessas peças em vários livros que hoje são fontes de referência sobre o tema.

Contudo, o principal referencial sobre 0 assunto é Gilberto Ferrez (1908 - 2000), principalmente no que se refere às suas exaustivas procura e catalogação da iconografia do Rio de Janeiro, dentro e fora do país, muito bem registrada nos dois volumes de Iconografia do Rio de Janeiro 1530-1890.

Não menos importante é Lygia da Fonseca Fernandes da Cunha (Lygia Cunha, 1922 - 2009) que como funcionária da Biblioteca Nacional, no Rio de Janeiro, atuou como bibliotecária, museóloga e pesquisadora da instituição, onde foi chefe da Seção de Iconografia e titular da Divisão de Referência Especializada, tendo deixado alguns textos sobre 0 conjunto de gravuras da Biblioteca (aqui se utilizou a reunião de seus textos organizada por Santos, Ribeiro e Lyra, 2010).

Quanto às manufaturas aqui citadas, muito pouco existe escrito sobre elas, mas também por terem sido fabricadas em série, são encontradas em diversas coleções particulares e lojas de antiguidades, e estão reproduzidas em alguns catálogos.

\subsection{As estampas}

Com o título Souvenirs de Rio de Janeiro, datado de 1834 e assinado pelo litógrafo J. Steinmann (aqui como editor), circulou, primeiro pela Europa e depois no Rio, um álbum de gravuras contendo12 vistas do Rio de Janeiro, sendo oito da cidade e quatro da província. As imagens foram gravadas por Friedrich Salathé na Suíça (a partir dos desenhos que Steinmann, Kretschnner e Victor Barrat fizeram no Brasil) e, posteriormente, impressas no processo de água-tinta e aquareladas em Paris. Cabe ressaltar que, naquele momento, não existia processo de impressão colorido.

A técnica da água-tinta se dá através da utilização de alguns líquidos corrosivos sobre a matriz de metal, previamente preparada com algum tipo de resina ou componentes granulados como açúcar, sal ou areia. Quando o ácido entra em contato com a placa, os grãos produzem uma textura que é responsável pelo tom acinzentado da obra. Assim, o resultado final é um desenho composto de áreas tonais de nuances suaves e não por linhas duras de contorno, como a gravação a entalhe. A coloração era feita, depois da impressão, uma a uma, por meio da técnica de aquarela. E muitas vezes por mais do que um artista, por vários deles, o que resulta em originais diferentes uns dos outros.

Do ponto de vista da construção do imaginário turístico que foi imputado ao Rio, mais interessante que as paisagens, no centro das pranchas do álbum, é a moldura que as envolvem. É uma cercadura de arabescos e guirlandas com abacaxis e outros detalhes da flora tropical, entremeados com vinhetas de pequenas cenas com personagens brasileiros (negros e índios), tais como um índio caçando uma onça e negras carregando crianças nas costas e frutas na cabeça. Não sendo esquecida a ideologia colonizadora: No centro e no alto da moldura, a caravela; no centro e embaixo, jesuítas - como se estivessem no alto de três púlpitos adornados por arcos que lembram as catedrais - abençoam os homens comuns, sentados abaixo deles, com os braços estendidos. 
Importante dizer que, antes disso, já se imprimiam gravuras no Rio de Janeiro. Também que o próprio Steinmann já havia anunciado no Jornal do Commercio, em 1932, estampas avulsas de negros, índios e vistas do Rio (provavelmente, as vistas do álbum eram as mesmas das gravuras avulsas), mas que esse álbum se destaca por ter sido o primeiro a se intitular Souvenirs de Rio de Janeiro. É conhecida também uma edição de 1935 da mesma obra que, no Rio de Janeiro, só seria anunciada no mesmo Jornal do Commercio em 1839, estando à venda na casa dos irmãos Laemmert - a livraria mais antiga do Brasil. Talvez esta casa tenha sido responsável pelos conhecidos exemplares em que a data aparece adulterada para 1839, provavelmente para fazer crer tratar-se de uma edição recente.

O sentido da palavra "souvenir" (lembrança) no trabalho de Steinmann diz respeito às recordações do artista suíço, que morara no Rio e naquele momento estava na Europa. E não ao seu público consumidor, inicialmente europeu. Outros álbuns de imagens do Rio seriam produzidos nas próximas décadas, e a mesma a palavra voltaria a aparecer, então se direcionando aos visitantes da cidade.

Pode-se dizer, então, que os álbuns de gravuras foram os primeiros suvenires do Rio, e que estes tentavam construir um imaginário de alteridade e exotismo associado a um novo mundo tropical ainda pouco conhecido. $E$, nesse caleidoscópio que se construía, a imagem do Rio foi se confundindo com a imagem do Brasil.

É importante que se diga também que, contemporaneamente ao momento de surgimento dos álbuns de vistas do Rio, estavam sendo publicados na Europa vários livros ilustrados sobre o Rio de Janeiro, como os de Debret, Maria Graham, Rugendas, e muitos outros. Contudo, nesses casos a ilustração é complemento do texto, enquanto - ao contrário - nas estampas a imagem é narrativa e o texto, quando existe, é complemento.

Entre outros álbuns com imagens da cidade, destacam-se Rio de Janeiro Pitoresco, de Buvelot e Moureau (c.1842-45), e Brasilian Souvenir - A Selection of the most peculiar costumes of the Brazils (sic.), de Ludwig e Briggs (c.1845-46). Chama-se a atenção para as palavras "pitoresco" e "peculiar" que nomeiam esses dois produtos. Do primeiro, existem, nos acervos brasileiros, exemplares colorizados e não colorizados, posto que, como foi dito, essa coloração a aquarela era feita exemplar a exemplar. As pranchas desse álbum, em geral, apresentam em destaque uma vista da cidade (natural ou construída) rodeada por desenhos menores de personagens urbanos e detalhes da flora local. Todas as pranchas são compostas por várias imagens e bananeiras, carros de boi, canoas e negros mascates fazem parte desse repertório.

Já o segundo álbum deixa completamente de lado a paisagem da cidade - que nestas alturas já era famosa por sua representação idílica -, para focar em personagens urbanos e cenas cotidianas. Nota-se, na seleção desses personagens e cenas, um olhar de curiosidade, uma lente de aumento para o diferente: guardas e policiais em uniformes paramentados, mascates e negras quitandeiras vendendo toda sorte de produtos, religiosos bonachões, negros (aparentemente) malemolentes sentados nas ruas, mulher sendo transportada numa liteira por dois escravos, etc. Apesar de os costumes da população brasileira - fossem de nobres ou escravos - soarem estranhos, curiosos, extravagantes ou até mesmo ridículos para 0 estrangeiro, estas imagens não parecem ter tido a intenção explícita de ridicularizar, mas de exaltar o diferente.

Por volta do ano de 1840, antes do álbum editado com Ludwig, o litógrafo Briggs já havia editado uma série numerada de estampas de tipos populares urbanos da cidade e seus costumes, também anunciada no Jornal do Commercio e, ainda antes disso (estimadamente entre os anos de $1830 \mathrm{e}$ 1832), Steinmann também publicou personagens urbanos do Rio de Janeiro: o Negro Capitão Buonaparte (que ocorre em trajes oficiais e em uma versão à paisana), o Filósofo do Cais do Paço, o Músico Policarpo e o Louco da Praia Grande. Estas imagens são raríssimas, segundo Ferrez (2000) as mais antigas litografias de tipos de rua executadas no país, sendo o único conjunto conhecido o que está depositado na Biblioteca Nacional.

Apesar de alguns exemplos muito conhecidos, essa iconografia do Rio ainda não está toda sistematizada, pois, segundo Ferrez (2000), a partir do ano de 1820 , publicou-se um grande número de álbuns de litografias de vistas ou de costumes da cidade, mas esta produção acontecia na Europa e, a maior parte, sem especificação impressa da data de edição.

Entre os produtos com créditos editoriais conhecidos, ainda podemos citar: Brasil pitoresco, histórico e monumental (álbum de vistas da cidade, de Alfred Martinet), O Rio de Janeiro e seus arredores (do Corcovado), também litografado por Alfred Martinet, Doze vistas do Rio de Janeiro (litografadas por Otto Speckter, a partir de pranchas de Karl Robert von Planitz) - todos editados entre os anos de $1847 \mathrm{e}$ 48 pela casa Laemmert. $E$, na década seguinte, entre 1856 e 57, são conhecidos: Brazil pitoresco e monumental (46 vistas de Pieter Godfred Bertichen, com textos de Augusto Zaluar) e Rio de Janeiro e seus arrabaldes - ambos editados pela Litografia Imperial de E. Rensburg; além do Álbum do Rio de 
Janeiro moderno, de Sébastian Auguste Sisson, editado pelo próprio autor.

Entende-se que essa produção iconográfica seriada, da cidade do Rio de Janeiro, encontrava mercado na Europa, onde despertava a curiosidade estrangeira, e também na própria cidade. 0 comércio no Rio de Janeiro tornar-se-ia, em pouco tempo, um mercado importante e crescente, atendendo a uma demanda cada vez maior de visitantes e até mesmo moradores (inclusive estrangeiros). Assim, também o nativo ia se habituando a valorizar a sua paisagem, ainda que influenciado pelos artistas viajantes, que tinham um "olhar de fora", passando "uma sensação de não estar de todo na sua composição", valendo-se de uma imagem prévia do país, muitas vezes em contradição com o seu cotidiano (SÜSSEKIND, 2006:33), mas também pelo estrangeiro aqui de passagem, que procurava levar para seu destino de retorno a confirmação dessa imagem prévia. Ainda que, reafirmando, essa confirmação fosse uma invenção em contradição com o usual local.

“(..) se a nossa impressão pode se basear não apenas na nossa lembrança, mas também na dos outros, nossa confiança na exatidão de nossa recordação será maior, como se uma mesma experiência fosse recomeçada não apenas pela mesma pessoa, mas por muitas (HALBWACHS, 2006:29)."

O turismo, a construção de destinos turísticos e, consequentemente, a invenção de seus suvenires - estão intimamente relacionados com a memória coletiva (conforme Halbwachs) e 0 imaginário coletivo. Sobre conhecer e lembrar-se de uma cidade, Halbwachs comenta que podemos ter a nossa atenção voltada para diferentes aspectos, mas reconhecer visualmente o que foi pré-conhecido faz parte de uma necessidade do turista de confirmação do que the foi anunciado (o que pode acontecer por meio de guias, filmes, literatura, matérias jornalísticas, publicidade, fotos e relatos de outros viajantes $-e$, mais recentemente, pelos canais da internet).

O desenvolvimento das técnicas de reprodução de imagem, associado à capacidade de representação da realidade através da fotografia, já fomentavam uma nova alfabetização visual que se dava, principalmente, por meio das revistas ilustradas. Essa amplificação do mundo visual alimentava o comércio de estampas, a troca de retratos e a formatação de álbuns familiares. 0 ver era cada vez mais estimulado no meio público ou privado. Não à toa, um pequeno retângulo de cartão passou a ser o centro das atenções de todas as classes sociais ao redor do mundo. O cartão-postal viabilizava em tempo e custo a circulação de notícias e imagens pelo mundo.
A ilustração chegou ao cartão-postal na década de 1890, reforçando a intenção do remetente pela narratividade da imagem, fazendo deste veículo um parceiro dos meios de locomoção modernos e verdadeiro garoto-propaganda das cidades e do turismo. Estima-se que os postais de paisagens tinham venda oito vezes maior que os de outros temas. No seu estreito relacionamento com o turismo e a publicidade, o cartão-postal também veiculou hotéis. $E$, hoje, passada a febre do colecionismo de postais, são basicamente as paisagens de teor turístico que ilustram aqueles que ainda sobrevivem.

Entre os primeiros postais com imagens do Rio de Janeiro, nos primeiros anos do século 20, destacam-se aqueles com fotografias de Marc Ferrez, tomadas ao longo de sua vida profissional, em edições da Marc Ferrez \& Filhos e Casa Marc Ferrez, ou ainda de terceiros. As reformas urbanísticas da cidade, no início da década de 1910, exatamente no auge da febre internacional dos cartões-postais, foram decisivas para a grande circulação de imagens do Rio pelo mundo afora.

Todas as grandes exposições nacionais e internacionais do final do século 19 mereceram seus postais comemorativos. No ano de 1889 , por ocasião da Exposição Universal de Paris, a representação da Torre Eiffel foi divulgada em 300 mil exemplares vendidos e expedidos em guichês instalados nos três andares da própria torre. No Rio de Janeiro, com as exposições de 1908 e 1922 não seria diferente. Os postais divulgaram e perpetuaram monumentos que 0 tempo levou. Grandes vistas panorâmicas da exposição de 1908 foram tomadas do Morro da Urca e da Baía de Guanabara.

Da Exposição do Centenário da Independência, além dos diversos pavilhões, os postais de Augusto Malta preservam na memória alguns monumentos construídos como, por exemplo, um curioso embarcadouro - na praça XV, próximo à Ponta do Calabouço para hidroaviões pertencentes a algumas das delegações estrangeiras presentes ao evento.

\subsection{Os artefatos}

Apesar das novidades (e modernidades) que a cidade ia oferecendo, no início do século XX, ainda era aquilo que já era pré-conhecido, e reconhecido coletivamente, que continuava a aparecer nas representações do Rio de Janeiro que circulavam no exterior. Nesse início do novo século, quando a fotografia já estava bastante disseminada, novos álbuns ilustrados (sem texto) surgiram, agora não mais com estampas produzidas a partir de desenhos, mas com clichês a partir de fotografias. São muitos os exemplos que tanto registraram áreas concisas (como 
Paquetá, Santa Teresa, Quinta da Boa Vista etc), como outros que tentavam cobrir todo o Estado do Rio de Janeiro, mostrando estradas e obras.

Além de estampas, álbuns, fotografias ou postais, a paisagem carioca começou a circular também em diversas superficies do mundo material utilitário e decorativo. Leques, baralhos, faianças, vasos, caixas, cinzeiros, pratos, copos, xícaras, fruteiras, bandejas, tabuleiros de jogos, porta-joias, etc. Enquanto o cartão-postal era o suporte para as novidades, os eventos, as inaugurações etc, os objetos de vidro, louça e cerâmica continuariam a perpetuar o menos efêmero - a paisagem carioca.

Um dos exemplos mais famosos da aplicação da paisagem do Rio de Janeiro em peças decorativas é a coleção de vidros assinados pelo artista art nouveau francês, Émile Gallé. Paisagens de outros cantos do mundo, como as da região de Alsácia e Lorena e do lago Como também mereceram a dedicação deste artista, cuja obra se consagra tanto pela sua plasticidade quanto pela sua proeza técnica, mas a série dedicada ao Rio é a única em que o artista grifou o nome da cidade. Suas composições são em geral emolduradas por plantas em primeiro plano. No caso do Rio de Janeiro, além das plantas tropicais, muito bem detalhadas, as montanhas do Pão de Açúcar, Corcovado e Pedra da Gávea são os motivos principais. Há exemplos também em que a paisagem construída - igrejas e casario colonial aparecem com bastante nitidez. Essas peças circularam basicamente no comércio europeu.

"Em mais de trinta anos de pesquisa, posso afirmar que quase a totalidade dos vasos [Gallé] encontrados procede da França. Mesmo que o depoimento de um dos maiores colecionadores dos Gallé-Rio, Baby Monteiro de Carvalho, indique que a série de vasos esteve à venda no Pavilhão da França da Exposição do Centenário da Independência, em 1922, no Rio de Janeiro (...) (Roiter, s/d:142)."

A suposta presença das peças no Pavilhão da França, em 1922, seria lembrança de infância do colecionador mencionado. Márcio Roiter (estudioso e também colecionador) menciona que algumas peças Gallé teriam sido vendidas nas principais joalherias do Rio, acondicionadas em estojos de veludo e seda (ROITER, s/d:142).

Não se tem notícias do artista ter estado no Rio, o que reforça a ideia de que a iconografia da cidade teve grande circulação na Europa no século 19. Morto no ano de 1904, Gallé deve ter produzido pessoalmente parte dessas peças e, como sua fábrica de vidro em Nancy continuou ativa até meados dos anos 1930, parte da produção deve ter sido feita posteriormente, por ajudantes que aprenderam com 0 mestre a aguçada técnica de gravação em vidro.

Também perpassando os primeiros anos do século $X X$, a porcelana, oriunda das mais importantes manufaturas europeias - em especial da Tchecoslováquia -, foi outro suporte para as paisagens cariocas, e também de seus monumentos arquitetônicos sob a forma de aparelhos de café, biscoiteiras, cinzeiros e bandejas.

O mercado dessas peças pode ter sido genérico - brasileiro e europeu, mas o antiquário Paulo Scherer (em depoimento pessoal em 14/08/2010) aposta na possibilidade de tais produtos terem sido encomendados por comerciantes brasileiros, a estas fábricas, para um comércio de luxo que existia na cidade, pois desde os tempos da família real, era comum o mercado nacional recorrer às manufaturas europeias para oferecer peças sofisticadas para 0 consumo interno.

Contudo os pratinhos de parede, procedentes em geral da Holanda e Bélgica - esses sim, mais baratos e muito comuns - eram claramente dedicados aos turistas. Além dos pratinhos, foi também razoavelmente comum, as xicrinhas (avulsas) de café. Chaveiros e plásticos (para colar em vidros de janelas de residências ou de carros) só apareceriam bem mais tarde. Essas peças de louça mais vulgares, mais simples, mais baratas, mais turísticas foram comumente usadas para veicular efemérides, além das novas paisagens urbanísticas, da reforma de Pereira Passos: o porto, o mangue, a avenida central.

A partir da década de 1930, quando o Rio já está consolidado como um destino turístico, porto de grandes transatlânticos - inclusive, não há dúvidas de que os suvenires de maior sucesso eram as bandejas que reproduziam as paisagens do Rio, utilizando-se de asas de borboleta furta-cor (predominantemente azul) sob tampo de vidro pintado. Importante lembrar, contudo, que essas borboletas só eram símbolo da cidade, pois a Floresta da Tijuca, seu principal habitat, era então um dos pontos turísticos mais visitados da cidade.

No filme de oito minutos - Rio de Janeiro: City of splendour - produzido pela Metro Goldwyn Mayer, no ano de 1936 - os dois últimos minutos são dedicados à técnica de confecção destes produtos. 0 narrador explica que tal design já existe há muitos anos e esclarece que 0 Brasil tem centenas de tipos diferentes de borboletas, muito mais coloridas que aquelas existentes na Europa ou nos Estados Unidos.

Entre as décadas de 1950 e 60, a febre recaiu sobre as caixas (principalmente, apesar de existirem outros objetos utilitários) confeccionadas em marchetaria com diversas tonalidades de madeira. 
Embora a confecção destas peças se desse no Paraná, estado do Sul do país, os únicos motivos que ilustravam estes trabalhos, segundo 0 antiquário Paulo Scherer (em depoimento pessoal em 14/08/2010), eram o pinheiro característico daquele estado e a paisagem do Rio de Janeiro. Os diversos tons de madeira, desse artesanato, exaltavam as riquezas naturais do Brasil, assim como as pedras semipreciosas, de outros estados brasileiros, vendidas nas lojas de suvenir do Rio de Janeiro.

As caixas de madeira, hoje não são mais fabricadas, mas as peças confeccionadas em pedras - sejam de forma bruta ou lapidada, ou ainda em arranjos esculturais, com formas de pássaros típicos da fauna nacional, continuam sendo produzidos. Aliás, parece ter havido uma revalorização desses objetos nos últimos anos. Evidência de que a cidade sempre teve e continua tendo um valor metonímico (parte pelo todo / todo pela parte) como símbolo do país.

Da mesma forma, ao longo dos anos 1950, $60 \mathrm{e}$ além, outros produtos representativos da diversidade da natureza brasileira, misturaram-se com produtos da cultura popular de diversas regiões do país, nas lojas de suvenir que já existiam, principalmente no bairro de Copacabana. Um anúncio da loja Zitrin \& Cia, localizada no Centro da Cidade, publicado no South American Handbook, no ano de 1957, informava ter qualquer tipo de pedra brasileira, assim como trabalhos em madeira, em pele de repteis e em asas de borboleta.

A ilustração do mesmo anúncio mostrava as pedras preciosas, a boneca baianinha, o boneco gaúcho, um tucano empalhado, as caixas de marchetaria, as bandejas de borboleta, e reproduções do Cristo Redentor. Além dos produtos da referida ilustração, a piranha empalhada (original da Amazônia) também começava a aparecer nas lojas de suvenir da cidade. Ainda os mesmos produtos da publicidade mencionada, tornam a aparecer em fotografia de uma loja de suvenir do Rio de Janeiro, dos anos 1950, pertencente ao acervo do banco de Imagend Images $2 \mathrm{You}$.

Hoje em dia - mundo globalizado e turismo massificado -, há cada vez menos produtos locais. Em qualquer cidade do mundo, os mesmos objetos (boné, camiseta, chaveiro, caneca...) se repetem em formas muito parecidas. No nordeste brasileiro, os ditos "artesanatos locais", especialmente de barro, se repetem exatamente iguais em diversas localidades.

Nas cidades litorâneas, as estampas de sol e praia, que adornam objetos e roupas, são exatamente as mesmas que aparecem no Caribe e em outros destinos internacionais. Fácil encontrar um "made in china" em vários deles.
Finalmente, redes de lojas de suvenires de aeroportos, como a Britt Shop - "A unique shopping experience!" -, estampa nas suas sacolas os países em que está presente: Costa Rica, Brasil, Chile, Colômbia, Peru, Uruguai, México, Antígua \& Barbuda, Curaçao, Equador.

Assim, à parte das sandálias havaianas (brasileiras, mas não cariocas), dos biquínis e das camisas dos times de futebol da cidade (não mais famosos que alguns times argentinos ou europeus), talvez a "novidade" em termos de suvenir da cidade do Rio de Janeiro sejam as estampas de favela. Ou seja: casinhas coloridas, juntinhas e apinhadas. 0 que começou como motivo de pinturas em pequenas telas, ofertadas nos tours de favela, hoje estão em estampas industriais em todas as lojas para turista da cidade.

\section{MEMÓRIA E PATRIMÔNIO}

O suvenir turístico é a concretude material e portátil do lugar visitado. Ora como um simples adorno, ora com uma pretensa função utilitária, ele age como um prolongamento da viagem e como âncora de memória em relação às experiências vividas na ocasião da experiência (turística ou não), posto que "A memória se enraíza no concreto, no espaço, no gesto, na imagem, no objeto" (NORA,1993, p.9). Quanto mais estrangeiro o destino turístico, mais importante a função deste objeto como âncora material de enraizamento.

Para permitir esse enraizamento, os "lugares de memória" (conceito chancelado pelo mesmo autor) precisam oferecer três sentidos simultâneos, embora, possivelmente, em graus diversos. São eles: material (por seu conteúdo demográfico), funcional (pois garante a cristalização da lembrança e a sua transmissão) e simbólico (pois caracteriza um acontecimento) (NORA, 1993, p.22). Lugares de Memória vão do objeto material e concreto, ao mais abstrato e funcional, embora os principais exemplos da categoria sejam espaços construídos - tais como arquivos, bibliotecas, museus, pantheons ou monumentos. Contudo,

"Mesmo um lugar de aparência puramente material, como um depósito de arquivos, só é lugar de memória se a imaginação o investe de aura simbólica. Mesmo um lugar puramente funcional, como um manual de aula, um testamento, uma associação de antigos combatentes, só entra na categoria se for objeto de um ritual. Mesmo um minuto de silêncio, que parece o extremo de uma significação simbólica, é, ao mesmo tempo, um corte material de uma unidade temporal e 
serve, periodicamente, a um lembrete concentrado de lembrar. Os três aspectos coexistem sempre [...]" (NORA, 1993, p.21-22).

Parece possível ampliar tal noção para os suvenires, pois os mesmos têm, necessariamente, existência material, funcional e simbólica. Suvenir é lembrança, evoca memórias, promove destinos e tangibiliza experiências (abstratas) vividas. Tal âncora de memória - física, concreta e transportável - do lugar visitado não está apenas nos objetos de suvenir, mas também nas imagens digitais e físicas.

Considerando que as imagens digitais precisam de suportes e meios físicos para "existirem", que as fotos em papel e os cartões-postais foram abandonados, e que os sites de viagem substituíram os guias impressos, tudo aquilo que se remete à viagem e envolve o contato físico, tem sido mais valorizado na contemporaneidade.

"Os lugares de memória nascem e vivem do sentimento que não existe memória espontânea, que é preciso criar arquivos, que é preciso manter os aniversários, organizar as celebrações, pronunciar as honras fúnebres, estabelecer contratos, porque estas operações não são naturais [...]. Se vivêssemos verdadeiramente as lembranças que eles envolvem, eles seriam inúteis. $\mathrm{E}$ se em compensação, a história não se apoderasse deles para deformá-los, transformá-los, sová-los e petrificá-los eles não se tornariam lugares de memória. É este vai-e-vem que os constitui: momentos de história arrancados do movimento de história, mas que lhe são devolvidos [...]" (NORA, 1993, p.13).

Os "lugares de memória" - no sentido genuíno de Pierre Nora - tais como museus e monumentos, transformam-se comumente em pontos turísticos e produzem seus próprios "objetos-âncora-lugares-dememória" tais como postais, suvenires, livros etc, numa busca constante de patrimonialização, memorialização, turistificação, e construção propriamente, da história e da identidade dos lugares.

Em decorrência, surge a categoria do "colecionamento". As coleções fazem parte da existência de lugares de memória, enquanto acervo, mas também está diretamente ligada à construção das histórias pessoais e das memórias dessas histórias, enquanto suvenir.

"Todo e qualquer grupo humano exerce algum tipo de atividade de colecionamento de objetos materiais, cujo efeito é demarcar domínio subjetivo em oposição ao "outro"." (GONÇALVES, 2003, p.26).
As coleções permitem a perpetuação identitária e simbólica de indivíduos ou grupos através de objetos que são ressignificados enquanto conjunto. $E$ que tornam a ser ressignificados quando vistos pelo "outro".

\section{CONSIDERAÇÕES FINAIS}

A intenção deste artigo foi a de apresentar aqueles que seriam os primeiros suvenires do Rio, entre os séculos XIX e XX. Especificamente tratamos de manufaturas brasileiras, surgidas nas décadas de 1930 e 1950, de caráter mais artesanal (ainda assim, produzidas em quantidades volumosas), onde a representação da cidade era mais sintética.

Historicamente, as narrativas presentes nos suvenires do Rio de Janeiro, mostraram-se como discursos eletivos de construção identitária da cidade enquanto destino de turismo. No século XXI, encontramos ainda a repetição de alguns desses discursos, perpetuando a cidade como um lugar miscigenógico e/ou sinestésico de Brasil, exaltando uma diversidade um tanto lembrada, um tanto inventada, um tanto memorializada.

Ao lado do chinelo de dedo, e do kit de caipirinha, ainda há lugar para uma toalha de praia que ilustra uma figura pantera, meio mulher, meio tigresa. E também uma camiseta estampada com bananeiras com as mangas com manchinhas de oncinha. Bem ou mal, essas imagens nos remetem tanto ao álbum do oitocentista Steinmann - que procurava dar conta de flora e fauna, índio e negro nos arabescos que emolduravam suas paisagens do Rio - quanto das piranhas empalhadas das lojas de suvenir dos anos 1950 e 60.

Mitos e arquétipos, imaginário coletivo, construção social contínua: o Rio como destino, e sua representação pelos suvenires que 0 visitante leva para casa, vem se processando desde a produção iconográfica dos primeiros viajantes que passaram pela cidade, exacerbando (e até inventando) as diferenças (bonitas, exóticas ou estranhas) em relação às suas origens.

Considerando ainda o processo de massificação das viagens, e do turismo como um todo, vê-se que os suvenires acompanham o mesmo processo. Hoje existem redes internacionais de lojas de suvenires, e grandes empresas fornecedoras de produtos, aparentemente locais, para as lojas dessas redes. No Brasil, um dos maiores distribuidores coloca seu selo "Souvenir Brasil", lado a lado com a gravação "Fabricado na China".

Turistas de viagens pré-fabricadas compram suvenires de massa. Turistas experienciais, aqueles que são protagonistas das suas viagens, aqueles que 
buscam (e, em geral, acreditam que encontram) vivências genuínas, vão procurar produtos que representem também genuinamente as características locais. Assim, o suvenir - e seu consumo -, vão ganhando significados tanto em relação às singularidades de quem os produz como as de quem 0 adquire.

Para Stuart Hall (2003:47), "as identidades nacionais não são coisas com as quais nós nascemos, mas são formadas e transformadas no interior da representação". Representação que se complica no meio do processo de globalização, onde até mesmo suvenires "locais" são fabricados (e vendidos) de forma global. "O que está acontecendo à identidade cultural na modernidade tardia?" pergunta o mesmo sociólogo jamaicano. "Especificamente, como as identidades culturais nacionais estão sendo afetadas ou deslocadas pelo processo de globalização?" Estariamos construindo não identidades?

Parte da cultura material de seu tempo, objetos preservam e contam histórias das quais foram testemunhas. Guardam narrativas na sua forma, no seu material, no seu processo de fabricação. Muitas vezes são registros de fatos que não foram memorializados de outra forma. Ainda assim, os objetos - principalmente os contemporâneos, produzidos em série e de acesso popular -, ainda não receberam a relevância que merecem nos campos de estudo das sociedades.

Para o turista, reconhecer presencialmente 0 que já é pré-conhecido faz parte de uma necessidade de confirmação daquilo que the foi anunciado, mesmo que isso soe déjà-vu. Assim, tanto o cartão postal (de outrora), quanto o suvenir (ainda hoje), que deveriam ser símbolo do singular e do local, acabam sendo também a confirmação daquilo que já se conhecia antes da viagem. Acabam subvertendo-se ao impessoal, global, disseminado.

\section{REFERÊNCIAS}

DOHMANN, Marcus. Cultura material: sobre uma vivência entre tangibilidades e simbolismos. Diálogo com a Economia Criativa, Rio de Janeiro, v.2, n.6, set/dez. 2017.

FERREZ, Gilberto. Iconografia do Rio de Janeiro 1530-1890, v. I e ll. Rio de Janeiro: Casa Jorge Editorial, 2000.

GONÇALVES, José R. S. O Patrimônio como categoria de pensamento. In ABREU, Regina; CHAGAS, Mário (orgs). Memória e patrimônio - Ensaios contemporâneos. Rio de Janeiro: Lamparina. 2003.

HALBWACHS, Maurice. A memória Coletiva. São Paulo: Centauro, 2006

HALL, Stuart. A identidade cultural na pós-modernidade. São Paulo: DP\&A. 2003.

MAFFESOLI, Michel. O imaginário é uma realidade. In Revista Famecos, Porto Alegre, n.15, ago. 2001.

NORA, Pierre. Entre a memória e a história: a problemática dos lugares, Projeto História, São Paulo: PUC-SP, n.10, dez.1993.

ROITER, Márcio. G. R. Disponível em www.artdecobrasil.com/materias/vasos.pdf. s/d.

SANTOS, Renata; RIBEIRO, Marcus V.; LYRA, Maria de L. V. (orgs.). O acervo iconográfico da Biblioteca Nacional. Estudos de Lygia da Fonseca Fernandes da Cunha. Rio de Janeiro: Biblioteca Nacional. 2010.

SÜSSEKIND, Flora. O Brasil não é longe daqui. São Paulo: Companhia das Letras, 2006. 